\title{
Design and Optimization of a High Gain Multiband Patch Antenna for Millimeter Wave Applications
}

\author{
A. Zaidi, A. Baghdad, A. Ballouk, A. Badri \\ Laboratory of Electronics, Energy, Automatics and Data Processing (EEA\&TI), Hassan II University, \\ Fst Mohammedia-Casablanca, B.P. 146 Mohammedia 20650, Morocco
}

\section{Article Info \\ Article history: \\ Received Dec 12, 2017 \\ Revised Jan 15, 2018 \\ Accepted Aug 20, 2018 \\ Keyword: \\ Circular patch antenna \\ DGS structure \\ Millimeter wave \\ Multiband antenna \\ Wideband antenna}

\begin{abstract}
This paper presents an enhanced Quadri-band microstrip patch antenna, using defective slots in the ground plane, designed to operate in the millimeter wave band, formulated using cavity model and simulated by an EM-simulator, based on finite element method: HFSSv15 (High Frequency Structure Simulator). The proposed antenna incorporates two symmetric patterns of "U" shaped slots with an "I" shaped slot engraved in the middle of the ground plane. The resulting antenna has four frequency bands; the first resonant frequency is located in the Ka band, at about $27 \mathrm{Ghz}$, the second at nearly $35 \mathrm{Ghz}$, the third at $41 \mathrm{Ghz}$ and the last one at $51 \mathrm{GHz}$. Those resonant frequencies could be shifted by tuning the slots dimensions introduced if the ground plane of the proposed antenna
\end{abstract}

Copyright (c) 2018 Institute of Advanced Engineering and Science. All rights reserved.

\section{Corresponding Author:}

Abir Zaidi,

Department of Electrical Engineering,

Laboratory of Electronics, Energy, Automatics and Data Processing (EEA\&TI), Hassan II University, Fst Mohammedia-Casablanca (B.P. 146 Mohammedia 20650 Morocco).

Email: abir.zaidi.z@gmail.com

\section{INTRODUCTION}

Moving away from encumbered areas of the spectrum to millimeter wave bands is the new approach used by antenna researchers and designers to manage the congestion of the spectrum in the traditional bands. For its important features such as large bandwidth availability thus: higher transfer rate, very low profile antennas for a given gain, or higher gain for fixed dimensions [1]. Patch antennas are increasingly being employed in the less congested bands, and using optimization techniques, they are capable to stand against the encountered problems in these areas, such as the high atmospheric attenuation, rain fade and free-space path loss, which reduces antenna gain [2].

Microstrip patch antennas are used in many applications and fields due to its various advantages such as low weight and profile [3], mechanical robustness and fluency of manufacture [4]. However, the radiation characteristics of the antenna degrades when we rise frequency up to the millimeter wave band [5], commonly called Extremely High Frequency band (EHF). Extensive research has yielded to experience new techniques to improve patch antennas and make them able to achieve multiple frequency bands. Several works were carried out into this topic; yet, the large majority of the proposed designs are dedicated for VHF (Very High Frequency) and UHF (Ultra High Frequency) applications, such as WIFI (2.4/5.2/5.8 GHz) [6], GPS (1.575 GHz) [7], WLAN [8], WIMAX [9] etc. Therefore, in order to improve spectrum usage in the millimeter wave band (from 30 to $300 \mathrm{GHz}$ ), EHF multiband patch antennas are a natural requirement.

Among the most common techniques used to improve the intrinsic antenna performance, there is DGS technique (Defected Ground Structure), widely used nowadays for its propitious advantages of upgrading gain, widening the bandwidth and improving antenna matching [10] [11]. This technique, as its name indicates, refers to geometric patterns engraved as a single or multiple defects in the ground plane of 
the antenna [12]. The insertion of those defects improves antenna performance by suppressing the harmonics of higher modes and enhancing radiation characteristics by extending antenna gain directivity and bandwidth [13]. The DGS method is employed as well in designing multiband antennas dedicated for different applications simultaneously, by subtracting several shapes from antenna ground plane [14] [15].

The present work aims to provide a new quadri band circular microstrip patch antenna dedicated to operate in the millimeter wave band, based on a conventional patch antenna, presented in a recent paper. The proposed model is improved using DGS technique in order to reach multiple frequency bands. A parametric study for the slots dimensions and position are carried out in this paper. Also, a comparison between another research and our proposed model is presented.

\section{ANTENNA DESIGN}

Circular microstrip patch antennas are investigated using cavity model: treated as a dielectric cavity, limited by electric conductors from top and bottom and by magnetic boundaries along the perimeter of the antenna [16]. Considering fringing fields, the radius of the circular microstrip patch antenna is computed using the following equation [17]:

$$
r_{e}=r \sqrt{1+\frac{2 h}{\pi r \varepsilon_{r}}\left[\ln \left(\frac{\pi r}{2 h}\right)+1.7726\right]}
$$

In order to achieve useful multiband patch antennas, we started from a basic circular microstrip antenna, enhanced using a single DGS placed in the ground plane center. The related work is dedicated to operate in the millimeter wave band, more specifically at $30 \mathrm{GHz}$, made with duroid (tm) substrate [18]. Table 1 presents physical dimensions of the conventional circular microstrip patch antenna of reference work:

Table 1. Physical dimensions of the Regular Patch Antenna

\begin{tabular}{lc}
\multicolumn{1}{c}{ Parameters } & Value \\
\hline Frequency of operation & $30 \mathrm{GHz}$ \\
Relative dielectric constant & 2.2 \\
Radius of the patch in mm & 1.97 \\
Width of the feed line in mm & 0.6 \\
Geometry of the notch in mm $(d \times g)$ & $0.6 \times 1.2$ \\
Substrate dimensions in mm & $10 \times 10$ \\
Substrate thickness & $0.31 \mathrm{mil}$ \\
\hline
\end{tabular}

In the related work, a single DGS defect is engraved in the center of the ground plane as shown in Figure 1.

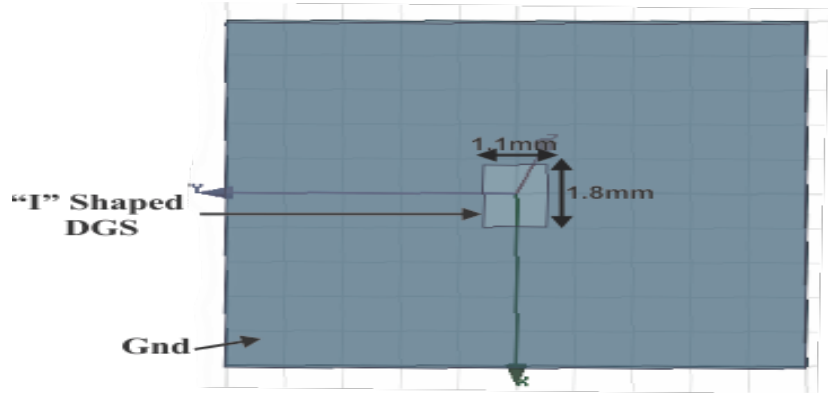

Figure 1. Geometry of the single unit cell DGS

The related work is extended in the present paper, by adding more slots in the ground plane in order to achieve more useful multibands, characterized by wide bandwidths, improved return loss and greater gain, suitable for millimeter wave frequencies. To do so, double " $U$ " shapes are being cut beside the rectangular slot from antenna ground plane. Figure 2 presents an illustration of the proposed model (a) and the geometry of the etched out shapes (b). 

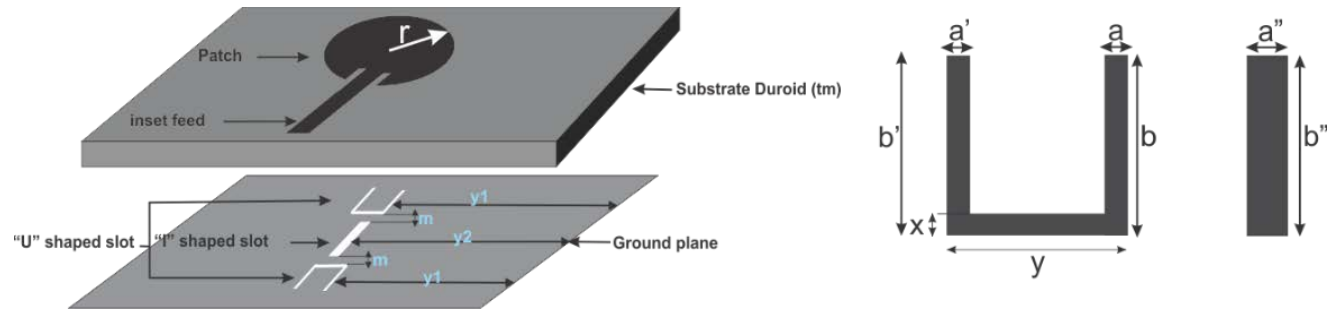

Figure 2. (a) Schematization of the proposed antenna (b) Geometry of the DGS slots

We will maintain the same size and position of the rectangular slot mentioned in the previous work, then we will introduce and vary the position and the dimensions of the double " $U$ " shaped slots, the resulting antenna resonates considerably on different frequencies. A parametric study for the " $U$ " shaped slot dimensions and position is carried out in the following section. Fractional bandwidth of an antenna is computed by the following equation [19]:

$$
F B W=\frac{f_{2}-f_{1}}{f_{c}}
$$

Where $f_{2}$ is the upper frequency, $f_{1}$ is the lower frequency and $f_{c}$ is the center frequency. Fractional bandwidth of wideband antennas is mainly $20 \%$ or more.

\section{RESULTS AND ANALYSIS}

All simulation results are carried out using ANSOFT software, HFSSv15 "High Frequency Structure Simulator”.

\subsection{Related Work}

Simulation results of the related work before and after optimization are summarized in Table 2

Table 2. Comparison of Antenna Parameters of the Related Work Before and After Optimization

\begin{tabular}{ccc}
\hline Parameter & before DGS & After DGS \\
\hline Resonating Frequency & $30 \mathrm{GHz}$ & $29.3 \mathrm{Ghz}$ \\
Return loss & $-31.24 \mathrm{~dB}$ & $-44.73 \mathrm{~dB}$ \\
Bandwidth & $2 \mathrm{GHz}$ & $2 \mathrm{Ghz}$ \\
Gain & $7.77 \mathrm{~dB}$ & $9.57 \mathrm{~dB}$ \\
VSWR & 1.08 & 1.1 \\
\hline
\end{tabular}

\subsection{Proposed Work}

Distance between the rectangular slot and "U” shapes is investigated firstly (refer to Figure 2 (a) parameter “m”).

a. Variation of position "m"

Table 3 summarizes the effect of the variation of the " $U$ " slots position, along the $x$-axis, on the electromagnetic field.

Table 3. E-Field values for different values of $m$

\begin{tabular}{lc}
\hline Value of “m” & E-field value \\
\hline$m=0.2 \mathrm{~mm}$ & $1,8034 \times 10^{4}$ \\
$m=0.3 \mathrm{~mm}$ & $1,6767 \times 10^{4}$ \\
$m=0.4 \mathrm{~mm}$ & $1,4026 \times 10^{4}$ \\
$m=0.5 \mathrm{~mm}$ & $1,3375 \times 10^{4}$ \\
$m=0.6 \mathrm{~mm}$ & $0,574 \times 10^{4}$ \\
$m=0.7 \mathrm{~mm}$ & $1,04 \times 10^{4}$ \\
$m=0.8 \mathrm{~mm}$ & $1,42 \times 10^{4}$ \\
\hline
\end{tabular}


From the obtained results, " $U$ " slots should be placed in the position where the E-filed is less intense [20] which means that " $\mathrm{m}$ " should be taken equal to $0,6 \mathrm{~mm}$. The E-field for the value $(m=$ $0,6 \mathrm{~mm}$ ) is shown in the Figure 4:

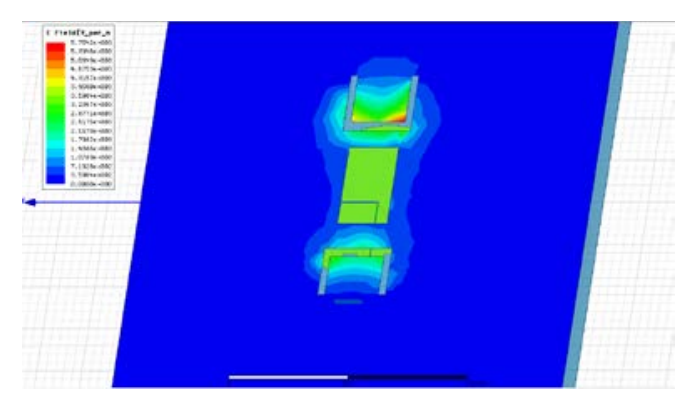

Figure 4. E-field for $\mathrm{m}=0,6 \mathrm{~mm}$

b. Variation of parameter "b":

We will consider changing the length of the "U" slot as shown Figure 2 (b). The following figure present the $S_{11}$ plot for different values of "b". Table 4 summarizes simulation results obtained from return loss plot from $1 \mathrm{~mm}$ to $1.5 \mathrm{~mm}$ :

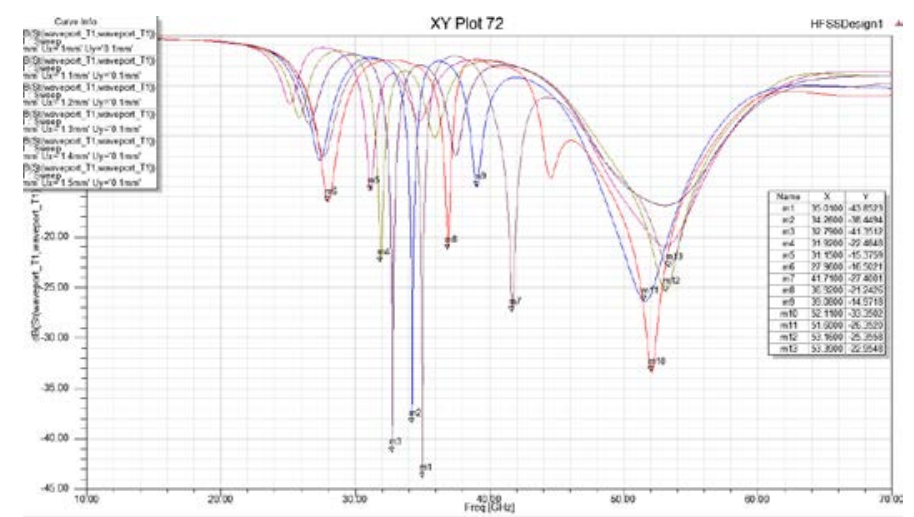

Figure 5. Return loss plot of different values of "b"

Table 4. Simulation Results of Tuning the Parameter "b"

\begin{tabular}{|c|c|c|c|c|c|c|c|}
\hline $\begin{array}{l}\text { Value of } \\
\text { "b" }\end{array}$ & $\begin{array}{c}\text { Operation } \\
\text { Frequencies }\end{array}$ & $S_{11}$ & Bandwidth & $\begin{array}{l}\text { Value of } \\
\text { "b" }\end{array}$ & $\begin{array}{c}\text { Operation } \\
\text { Frequencies }\end{array}$ & $S_{11}$ & Bandwidth \\
\hline $1 \mathrm{~mm}$ & $\begin{array}{l}\text { 28Ghz } \\
37 \mathrm{Ghz} \\
52 \mathrm{Ghz}\end{array}$ & $\begin{array}{l}-16,5 \mathrm{~dB} \\
-21,25 \mathrm{~dB} \\
-33,4 \mathrm{~dB}\end{array}$ & $\begin{array}{c}1,63 \mathrm{Ghz} \\
0,8 \mathrm{Ghz} \\
13,11 \mathrm{Ghz}\end{array}$ & $1.3 \mathrm{~mm}$ & $\begin{array}{l}\text { 32,8Ghz } \\
\text { 37,5Ghz } \\
\text { 53,1Ghz }\end{array}$ & $\begin{array}{l}-41,3 \mathrm{~dB} \\
-12 \mathrm{~dB} \\
-17 \mathrm{~dB}\end{array}$ & $\begin{array}{c}0,85 \mathrm{Ghz} \\
0,74 \mathrm{Ghz} \\
10,27 \mathrm{Ghz}\end{array}$ \\
\hline $1.1 \mathrm{~mm}$ & $\begin{array}{c}27,64 \mathrm{Ghz} \\
34,85 \mathrm{Ghz} \\
41,7 \mathrm{Ghz} \\
53,5 \mathrm{Ghz}\end{array}$ & $\begin{array}{l}-12 \mathrm{~dB} \\
-44 \mathrm{~dB} \\
-27,5 \mathrm{~dB} \\
-23 \mathrm{~dB}\end{array}$ & $\begin{array}{l}1,03 \mathrm{Ghz} \\
0,83 \mathrm{Ghz} \\
1.84 \mathrm{Ghz} \\
10,4 \mathrm{Ghz}\end{array}$ & $1.4 \mathrm{~mm}$ & $\begin{array}{l}\text { 31,9Ghz } \\
35,9 \mathrm{Ghz} \\
53,1 \mathrm{Ghz}\end{array}$ & $\begin{array}{c}-22,5 \mathrm{~dB} \\
-10,15 \mathrm{~dB} \\
-25,4 \mathrm{~dB}\end{array}$ & $\begin{array}{l}0,82 \mathrm{Ghz} \\
9,4 \overline{2} \mathrm{Ghz}\end{array}$ \\
\hline $1.2 \mathrm{~mm}$ & $\begin{array}{c}27,4 \mathrm{Ghz} \\
34,3 \mathrm{Ghz} \\
39 \mathrm{Ghz} \\
51,6 \mathrm{Ghz}\end{array}$ & $\begin{array}{c}-12,4 \mathrm{~dB} \\
-38,4 \mathrm{~dB} \\
-15 \mathrm{~dB} \\
-26,3 \mathrm{~dB}\end{array}$ & $\begin{array}{c}1.01 \mathrm{Ghz} \\
0,78 \mathrm{Ghz} \\
0,95 \mathrm{Ghz} \\
10 \mathrm{Ghz}\end{array}$ & $1.5 \mathrm{~mm}$ & $\begin{array}{c}\text { 31,17Ghz } \\
\text { 53Ghz }\end{array}$ & $\begin{array}{c}-15,4 d B \\
-21 d B\end{array}$ & $\begin{array}{l}0,72 \mathrm{Ghz} \\
10,5 \mathrm{Ghz}\end{array}$ \\
\hline
\end{tabular}

From the classified results, we can deduce that the antenna resonates at multiples frequencies, and the variation of the length of the "U" slots affects considerably the operation frequency, the return loss and bandwidth of our proposed antenna. The choice of the value of " $b$ " depends mainly on the frequencies of the desired applications. 
c. Variation of parameter “a”:

We will consider the value $(b=1.1 \mathrm{~mm})$ and we will change the value of the parameter "a" (width of the "U" slot). Figure 6 presents the $S_{11}$ plot for different values of "a”. From obtained results presented in Table 5, we can notice that tuning the width of the "U" slots affects considerably return loss; however, it does not have much influence on operation frequency of our antenna. We can also observe that in all cases the antenna presents a high gain in all frequencies especially when we set "a" at $0.14 \mathrm{~mm}$. The obtained gain results for frequencies $27.48 \mathrm{GHz}, \quad 34.88 \mathrm{GHz}, \quad 41 \mathrm{GHz}, \quad 51.4 \mathrm{GHz}$ are respectively $10.46 d B, 13,27 d B, 11,07 d B$ and $7.65 d B$ as shown in Figure 8. Also, our proposed antenna is characterized by a large bandwidth located in the V-band (>40 GHz), the calculation of the FBW for different values of "a" and "b" gives a result greater than $20 \%$, which proves that our proposed antenna is a wideband antenna as shown in Figure 7.

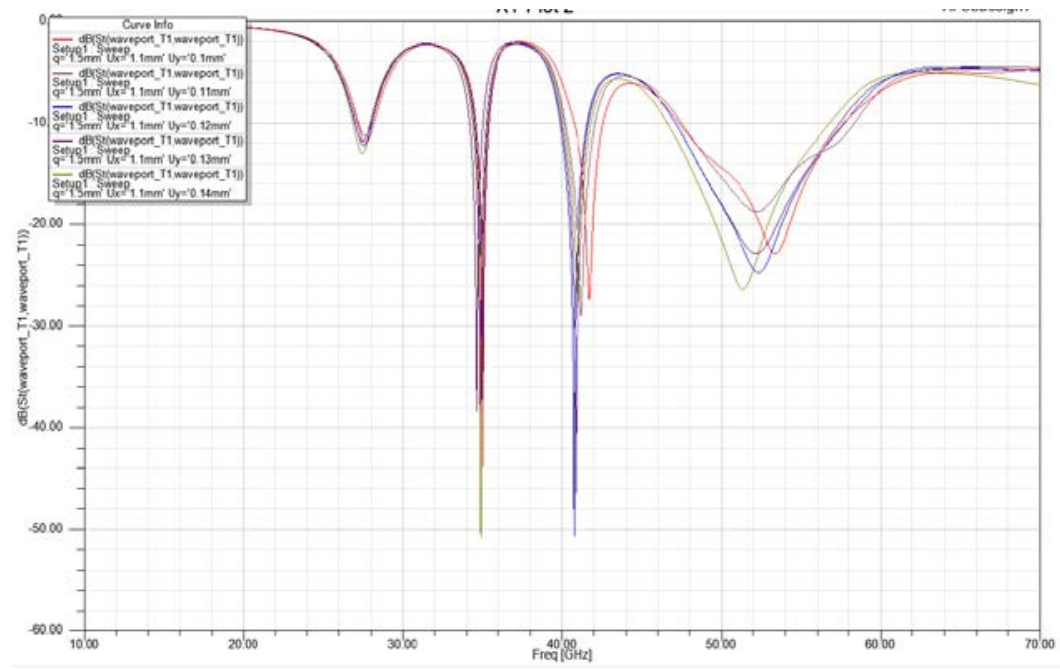

Figure 6. Return loss plot of different values of "a"

Table 5. Simulation Results of Tuning the Parameter "b"

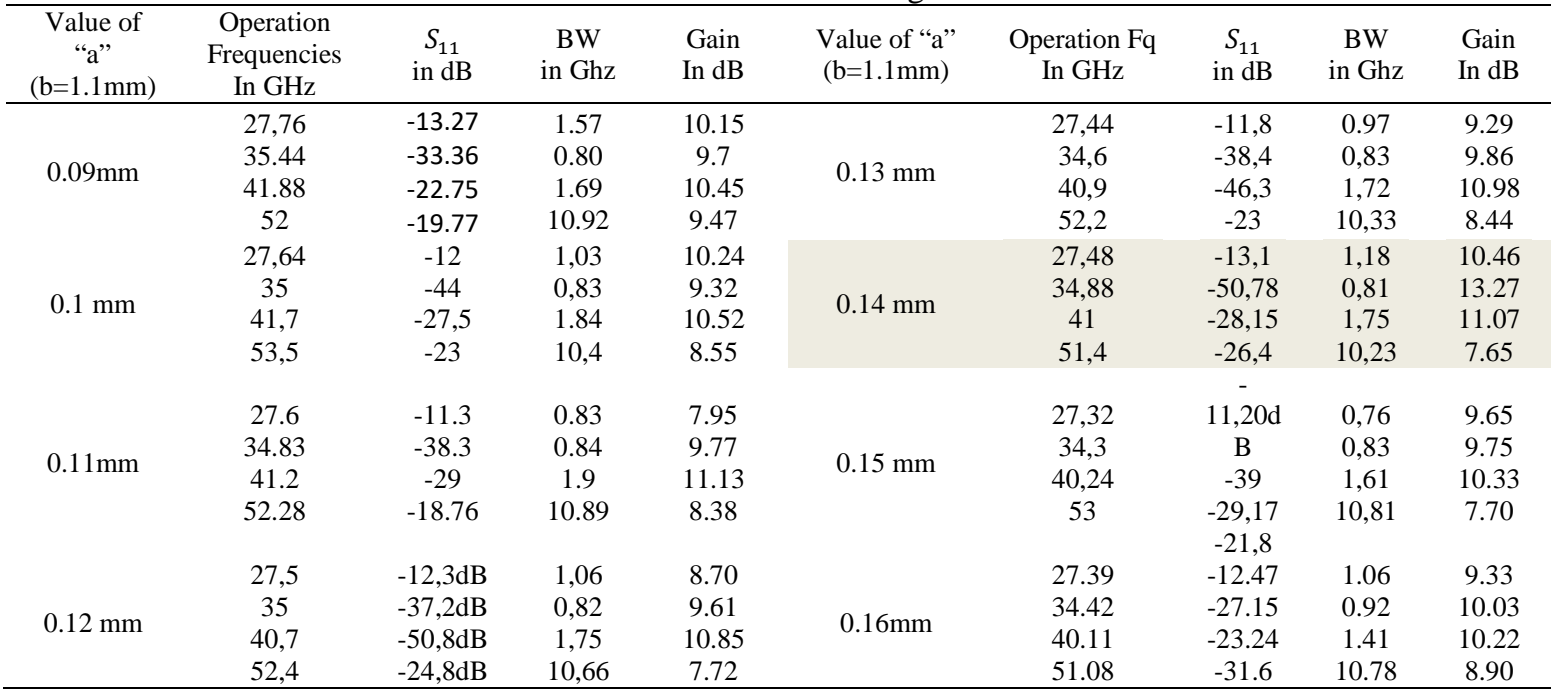




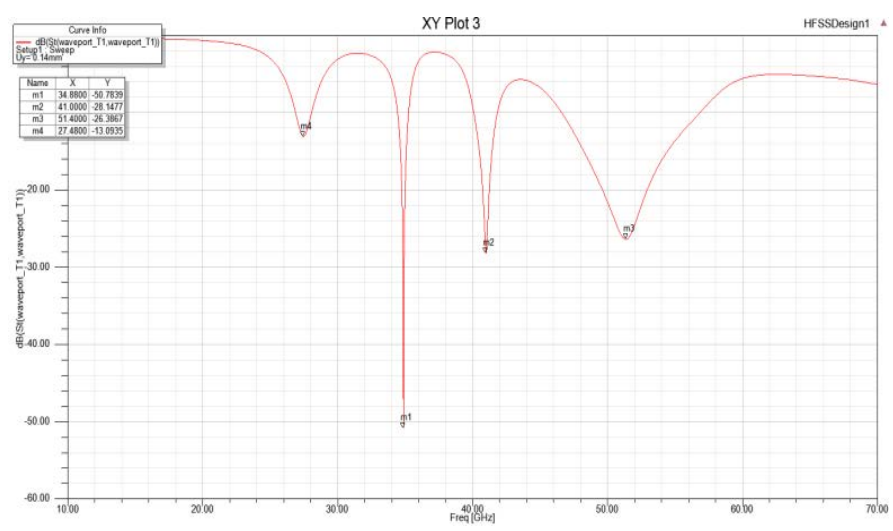

Figure 7. Return loss plot for $\mathrm{a}=0.14 \mathrm{~mm}$

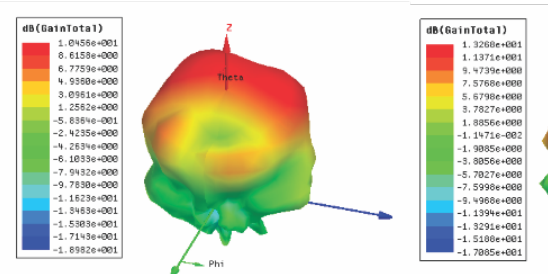

(a)

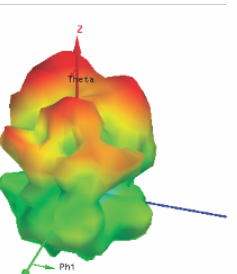

(b)

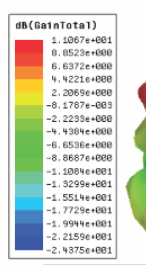

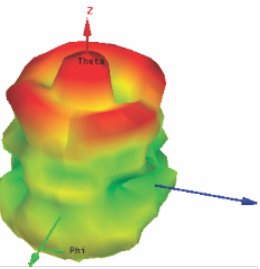

(c)
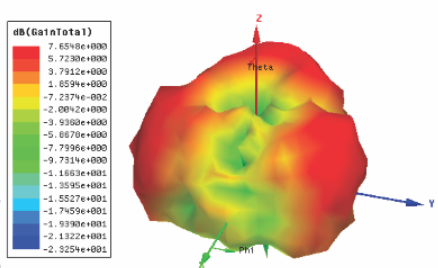

(d)

Figure 8. (a)3D gain polar plot at $\mathrm{f}=27.48 \mathrm{GHz}$; (b)3D gain polar plot at $\mathrm{f}=34.88 \mathrm{GHz}$; (c) $3 \mathrm{D}$ gain polar plot at $\mathrm{f}=41 \mathrm{GHz}$; (d) $3 \mathrm{D}$ gain plot at $51.4 \mathrm{GHz}$

Figure 9 presents input impedance plot for obtained frequencies when $(\mathrm{b}=1.1 \mathrm{~mm}$ and $\mathrm{a}=0.14 \mathrm{~mm})$ (a) and VSWR values of proposed antenna when $(b=1.1 \mathrm{~mm}$ and $a=0.14 \mathrm{~mm})(\mathrm{b})$.
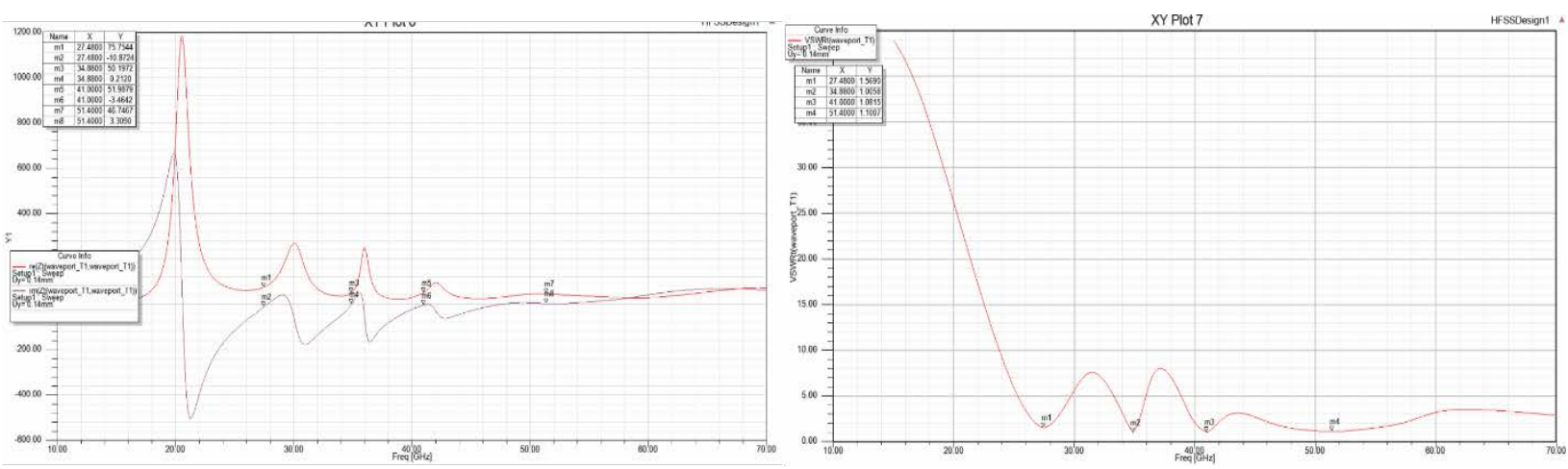

Figure 9. (a) Input impedance of resulting antenna; (b) VSWR plot of resulting antenna

Input impedance and VSWR values of our proposed antenna when we set "b" at $1.1 \mathrm{~mm}$ end “a” at $0.14 \mathrm{~mm}$ are listed in Table 6 .

Table 6. Input Impedance Results Corresponding to the Dimensions $(\mathrm{a}=0.11 \mathrm{~mm}$ and $\mathrm{b}=1.1 \mathrm{~mm})$

\begin{tabular}{ccc}
\hline Frequency & Input impedance values (re) & VSWR \\
\hline $27,48 \mathrm{Ghz}$ & $75,75 \Omega$ & 1.57 \\
$34,88 \mathrm{Ghz}$ & $50,19 \Omega$ & 1.006 \\
$41 \mathrm{Ghz}$ & $51,9 \Omega$ & 1.08 \\
$51,4 \mathrm{Ghz}$ & $46,75 \Omega$ & 1.101 \\
\hline
\end{tabular}


From input impedance values, we can observe that the proposed antenna is well matched in three frequencies in the EHF band, although poorly matched in the frequency around the Ka band. On other hand, VSWR values proves that antenna is matched to the transmission line and more power is delivered to the antenna.

\subsection{Comparison with Another Work}

Table 7 presents a comparison between our proposed model and the antenna presented in another research [21]:

Table 7. Comparaison between the Proposed Antenna and Another Work

\begin{tabular}{ccccc} 
Ref & Operating Frequency & Return loss & Gain & VSWR \\
\hline \multirow{2}{*}{ Other } & 42 & $-19 \mathrm{~dB}$ & $5.79 \mathrm{~dB}$ & $\sim 2$ \\
work [21] & 51.5 & $-24 \mathrm{~dB}$ & $3.98 \mathrm{~dB}$ & $\sim 1.1$ \\
& 60 & $-19.5 \mathrm{~dB}$ & $5.29 \mathrm{~dB}$ & $\sim 1.95$ \\
Proposed & 27,48 & $-13,1$ & 10.46 & 1.57 \\
work & 34,88 & $-50,78$ & 13.27 & 1.006 \\
& 41 & $-28,15$ & 11.07 & 1.08 \\
& 51,4 & $-26,4$ & 7.65 & 1.101 \\
\hline
\end{tabular}

NB: VSWR values of reference work [21] are estimated from VSWR vs Frequency plot presented

From summarized results listed in Table 7, we can observe that our antenna supports more frequencies comparing to the other work, including a wideband at $51.4 \mathrm{GHz}$, also a better return loss and VSWR values. Furthermore, we reached an important gain in all frequencies especially at $34.88 \mathrm{GHz}$ with a value of $13.27 \mathrm{~dB}$.

\section{CONCLUSION}

The presented paper extends an existing work dedicated for applications in the millimeter wave band. The regular antenna presented in the related work resonates in a single band around 30Ghz. Our paper based on the same regular shaped antenna elaborates the design of multiband microstrip patch antenna that operates mainly around the frequencies $27 \mathrm{GHz}, 35 \mathrm{GHz}, 41 \mathrm{GHz}$ and $51 \mathrm{GHz}$. The parameters such as gain, return loss, operation frequency, VSWR, input impedance and bandwidth are tuned by changing the position and dimensions of the DGS slots incorporated in the ground plane of the antenna.

The proposed model is well matched, characterized by a wide bandwidth (more than $10 \mathrm{GHz}$ ), an enhanced return loss, and a strong gain (more 13dB around $34 \mathrm{GHz}$ ). Comparing the presented quadri-band antenna with another existing research dedicated for millimeter wave frequencies, we observed that our antenna presents stronger performance in terms of gain, return loss and VSWR, making this proposed prototype an excellent candidate for future applications in the millimeter wave band.

\section{REFERENCES}

[1] S. Rangan, Theodore S. Rappaport, E. Erkip, "Millimeter-Wave Cellular Wireless Networks: Potentials and Challenges”, Proceedings of the IEEE .2014; Vol 102(3): 366 - 385

[2] J. Zhan, J. Wen, L. Sun, X. Shu, “Design of $60 \mathrm{GHz}$ mm-wave Patch Antenna Arrays”, Communication Technology (ICCT), IEEE 16th International Conference. Hangzhou, China. 2015

[3] D. Fistum, D. Mali, M. Ismail, "Bandwidth Enhancement of Rectangular Microstrip Patch Antenna using Defected Ground Structure”, Indonesian Journal of Electrical Engineering and Computer Science.2016;Vol 3(2): $428-434$

[4] K. Parashar, "Design and Analysis of I-Slotted Rectangular Microstrip Patch Antenna for Wireless Application", International Journal of Electrical and Computer Engineering (IJECE). 2014; Vol 4(1): 31-36

[5] R. Mishra, P. Kuchhal, A. Kumar, "Effect of Height of the Substrate and Width of the Patch on the Performance Characteristics of Microstrip Antenna”, International Journal of Electrical and Computer Engineering (IJECE). 2015; Vol 5(6): 1441-1445

[6] Z. Weng, D. Guo, Y. Wu, M. Li, J. Hu, W. Zeng, X. Li, S. Zeng, “A 2.45GHz Microstrip Patch Antenna Evolved For WiFi Application” Evolutionary Computation (CEC), IEEE Congress.Sendai, Japan. 2015

[7] R. Mittra, R. Yang, M. Itoh, M. Arakawa, "Microstrip patch antenna for GPS applications" Antennas and Propagation Society International Symposium. AP-S. Digest.Ann Arbor, MI, USA.1993

[8] T. Jayachitra, V.K Pandey and Anshuman Singh, "Design of Microstrip Patch Antenna for WLAN Applications", International Journal of Advanced Research in Electrical, Electronics and Instrumentation Engineering. 2014; Vol 3(3): $17-22$ 
[9] M. Aneesh, M. Gulman Siddiqui, J.A Ansari, A. Singh, Kamakshi, "Inset Feed Toppled H-Shaped Microstrip Patch Antenna for PCS/WiMAX Application”, Indonesian Journal of Electrical Engineering and Computer Science. 2016; Vol 1(2): $365-370$

[10] S. Abirami, S. Bavithra, S. Keerthika and P. Rengalakshmi, "Compact microstrip patch antenna for WLAN application”, SSRG International Journal of Electronics and Communication Engineering (ICRTECIT). 2017; special issue: $177-181$

[11] S. Elajoumi, A. Tajmouati, A. Errkik, Am. Sanchez, M. Latrach, "Microstrip Rectangular Monopole Antennas with Defected Ground for UWB Applications", International Journal of Electrical and Computer Engineering (IJECE). 2017; Vol.7(4): 2027-2035

[12] D. Guha \& Yahia M. M. Antar, "Defected Ground Structure for Microstrip Antennas", Microstrip and Printed antennas. page: 413.

[13] S. Sharma, G. Kumar, “A dual Wideband Stair Shape Microstrip Patch Antenna for C \& X Band”, International Journal of Electronics and Communication Engineering (IJECE). 2016; Vol. 5(4): 1-8

[14] P. Bhagat, P. Jain, "Triple Band Microstrip Patch Antenna with Dual U Slot For WLAN/WIMAX Applications", SSRG International Journal of Electronics and Communication Engineering (SSRG-IJECE). 2014; Vol. 1(7): 44-49

[15] Amrutha G M, Reshmi Haridas M, Sreedevi T N, Shibul P, Sumi M, "Dual band microstrip patch antenna and a wide band reject filter using DGS”, SSRG International Journal Electronics and Communication Engineering(ICET'17). 2017; Special Issue: 52-55.

[16] N.T. Markad, R.D. Kanphade, D.G Wakade, “Design of Cavity Model Microstrip Patch Antenna”, Computer Engineering and Intelligent Systems. 2015; Vol.6(4)

[17] K. Guney, N. Sarikaya, "Resonant Frequency Calculation for Circular Microstrip Antennas with a Dielectric cover using Adaptive Network-Based Fuzzy Inference System optimized by various Algorithms", Progress In Electromagnetics Research, PIER 72. 2007: 279-306

[18] A. Zaidi, A. Baghdad, A. Ballouk, A. Badri, "Design and optimization of an inset fed circular microstrip patch antenna using DGS structure for applications in the millimeter wave band". Wireless Networks and Mobile Communications (WINCOM), 2016 International Conference.Fez, Morocco. 2016

[19] B.-K. Ang and B.-K. Chung, "A wideband E-Shaped microstrip pach antenna for 5-6 Ghz wireless communications" Progress In Electromagnetics Research, PIER 75. 2007; 397-407

[20] I. Tabakh M. Jorio N. El Amrani El Idrissi, "MPA radiation characteristics evolution through a DGS size reduction study”, Wireless Networks and Mobile Communications (WINCOM), 2016 International Conference. Fez, Morocco. 2016

[21] A. H. Jabire, A. Abdu and S. Salisu, "Multiband Millimeter wave T-shaped antenna with optimized patch parameter using Particle Swarm Optimization”, Nigerian Journal of Technology (NIJOTECH). Vol. 36, No. 3, July 2017, pp 904-909.

\section{BIOGRAPHIES OF AUTHORS}

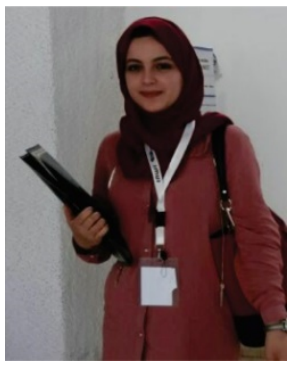

Abir Zaidi born in Fez, Morocco in July 23, 1991. In 2012 She had got her licence degree in Electronics, Telecommunications and Computer Systems at Fez University of Sciences and Technology, then she had got a Master's degree in Microelectronics, Telecommunication and Industrial Data processing at the same University. She is currently a Ph.D. student in the Laboratory of Electronics, Energy, Automatics and Data Processing (EEA\&TI) Hassan II University, Mohammedia-Casablanca, Morocco. Her works studies and interests are focused on the design and the optimization of the performance of single and multiband microstrip patch antennas to operate in the millimeter wave band, under the supervision of Pr. A. Baghdad, Professor in Electrical engineering department at the same University

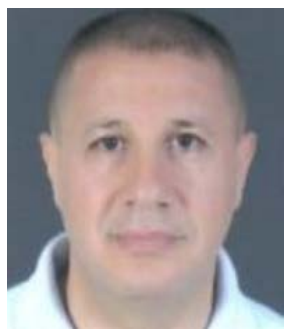

Abdennaceur Baghdad is a holder of a doctorate in Electronics in 1992 at the University of Lille-France. $\mathrm{He}$ is University Professor (PES) at the University Hassan II Mohammedia Casablanca- Morocco (FSTM) where he teaches the electronics, Hyperfrequencies, antenna and telecommunication. He is a member of the laboratory EEA\&TI (Electonics, Energy, Automatic and information Processing). The research works of A. Baghdad concerns the communication and Information Technology (Electronics Systems and Telecommunication). He supervises doctoral theses and he is a coauthor of several national and international publications. He was a member of steering committees of three international congresses in the same domain of research. 


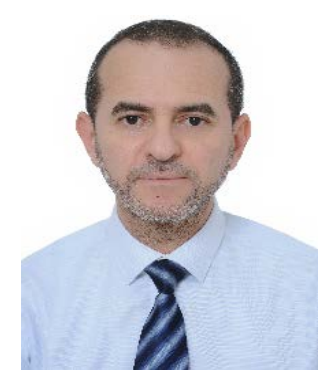

Abdelhakim Ballouk is a University Professor at the Faculty of Science and Technology Mohammedia - Hassan II University of Casablanca. Member of the Laboratory of Electronics, Energy, Automatics \& Information Processing. He obtained his Doctorate from the University of Bordeaux France in 1992, in the field of Automatics. The fields of research are Automatic notably robust controls, predictive commands etc. He is also specialized in Telecommunications notably antenna engineering.

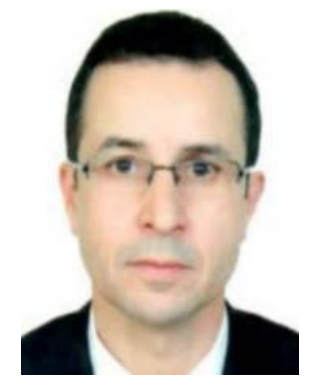

Abdelmajid Badri is a holder of a doctoratein Electronics and Image Processing in 1992at the University of Poitiers - France. In 1996, he obtained the diploma of the authorizationto Manage Researches (Habilitation à Dirigerdes Recherches: HDR) to the University of Poitiers - France, on the image processing. He is University Professor (PES-C) at the University Hassan II Mohammedia-Casablanca Morocco (FSTM) where he teaches the electronics, the signal processing, image processing and telecommunication. He is a member of the laboratory EEA\&TI (Electonics, Energy, Automatic and information Processing) which he managed since 1996. The research works of A. Badri concerns the communication and Information Technology (Electronics Systems, Signal/Image Processing and Telecommunication). He is qualified by CNU-France in 61th section: informatics engineering, automatic and signal processing. He managed several doctoral theses. $\mathrm{He}$ is a co-author of several national and international publications. He is responsible for several research projects financed by the ministry or by the industrialists. He was member of several committees of programs of international conferences and president of three international congresses in the same domain. He is a member and responsible in several scientific associations in touch with his domain of research. 